tude and obliquity for each day of the period 1900-59, based on new series expansions by E. W. Woolard. The numerical calculations were performed by H.M. Nautical Almanac Office. The new series expansions are being used in the national ephemerides from 1960. The calculations have been extended backwards to enable observers to make improved reductions of recent observations of the Sun, Moon and planets.

\section{New High-power Xenon-Arc Lamp}

A NEW lamp, a compact 5,000-W. xenon-arc lamp, which is nearly three times as bright as the Sun and which will have applications in searchlight and projection equipment, has been developed by the U.S. General Electric Company. The light produced by the lamp totals 275,000 lumens, or 55 lumens/W. The lamp is the second of its kind; the first was a $2,000-W$. xenon arc lamp and has been available for several months. Its first use is in a solar simulator for space vehicle investigations. In the visible, the light simulates sunlight, and its total spectrum, including the ultra-violet and infra-red, approximates closely to solar radiation. The lamp has a high degree of stability and of freedom from noise, smoke and fumes. Housed in a parabolic reflector, the lamp throws a powerful beam of light, and, used as a large searchlight, could throw a beam of $10^{9}$ candle-power, sufficient to enable a person to read a newspaper at a distance of about 15 miles from the source. Another expected application is to optical masers. As a source of intense infra-red radiation it will be useful in connexion with solar-type furnaces. The lamp is a direct-current light source in an ellipsoidal-shaped quartz bulb. The bulb is only about $3 \frac{1}{2} \mathrm{in}$. in diameter and $4 \frac{1}{4} \mathrm{in}$. in length although the overall length of the lamp is slightly above $19 \mathrm{in}$. The bulb houses two tungsten electrodes with an are gap of $8 \mathrm{~mm}$. and the are operates in a high pressure of xenon. A high voltage is applied to start the lamp and a current of $145 \mathrm{amp}$. flows across the arc from the cathode to the large anode, which weighs $\frac{3}{4} \mathrm{lb}$. The anode reaches a temperature of $6,000^{\circ} \mathrm{F}$. The lamp is expected to have an operating life of $1,000 \mathrm{hr}$. Further details of the lamp are available from the International General Electric Co. of New York, Ltd., 296 High Holborn, London, W.C.1.

\section{The First Bragg Lecture}

The first public Bragg Lecture (admission free) will be given by Prof. P. P. Ewald, president of the International Union of Crystallography, on the subject "William Henry Bragg and the New Crystallography" at 5.15 p.m. on June 7, in the Arts Lecture Theatre of the University of Leeds, and at 5.15 p.m. on June 13, at the Royal Institution, 21 Albemarle Street, London. The Lecture this year is part of the centenary celebration of the birth of Sir William Bragg. It is also a prelude to the jubilee celebration of the discovery of X-ray diffraction by crystals, to be held in July in Munich, where Prof. Max von Laue suggested and Drs. Friedrich and Knipping carried out their first famous experiment, an experiment which was the result of a question asked by the young research student, Paul Ewald, fifty years ago. The Bragg Lecture will be given once in three years at one or more of the Universities of Cambridge, Leeds, London and Manchester or at the Royal Institution, London, in which places Sir William Bragg and his son, Sir Lawrence Bragg, have carried on their research work. Sir Lawrence Bragg will take the chair on June 13.

\section{British Electrical Power Convention}

ThE fourteenth British Electrical Power Convention will be held in Brighton during June 4-7. The theme of the Convention will be "The British Electrical Industry in the World Scene", and the programme will include: British engineering services overseas (Mr. A. E. Powell, Merz and McLellan); planning for expansion in electricity supply (Mr. R. S. Edwards, Electricity Council, and Mr. D. Clark, Central Electricity Generating Board); automation the central industrial theme of the '60's ? (Sir Leon Bagrit, Elliott Brothers (London), Ltd.). The Citrine Lecture, "The Snowy Mountains Scheme", will be delivered by Sir William Hudson, commissioner of the Snowy Mountains Hydro-Electric Authority. Further information can be obtained from the press officer, Mr. Stanley Oxley, British Electrical Development Association, 2 Savoy Hill, London, W.C.2.

\section{Announcements}

Dr. B. K. Davison has been appointed development chomist in the Development and Research Department of the International Nickel Co. (Mond), Ltd. He is concerned with the chemical and chemicophysical aspects of the Department's work, with particular reference to the established and potential industrial applications of the Company's chemical products. Dr. Davison was formerly organic research manager at Hardman and Holden, Ltd., of Manchester. Previously he was with Imperial Chemical Industries, Ltd., Billingham, and the Imperial College of Tropical Agriculture, Trinidad.

THE seventh International Congress on Alpine Meteorology will be held in Sauze d'Oulx-Sestriere, Italy, during September 3-6. Further information can be obtained from the Secretary, Società Italiana di Geofisica e Meteorologia, P.O. Box 3145, Genova.

The National Vegetable Research Station is holding an open day on July 19, when visitors will be able to inspect the laboratories, and see some of the techniques used in a modern research station. Further information can be obtained from Mr. G. Lesson, National Vegetable Research Station, Wellesbourne, Warwick.

A symposium on "Reproductive and Parental Behaviour", arranged by the Association for the Study of Animal Behaviour, will be held in Oxford during July 11-13. The programme will include a visit to the Animal Behaviour Research Group of the Department of Zoology, University of Oxford. Further information can be obtained from Dr. J. B. Free, Rothamsted Experimental Station, Harpenden, Herts.

Errata. In the article appearing in the March 31 issue of Nature, entitled "Classification and Nomenclature of Enzymes and Coenzymes", by Prof. R. H. S. Thompson, on p. 1229, col. 1, line 3 from bottom (footnote), " $K_{+n}, K_{-n}$, velocity constants of ..." should read " $k_{+n}, k_{-n}$, velocity constants of ...". and on p. 1229, col. 2, line 11 from top, "Thus $K_{+n}$ will denote. . ." should read: "Thus $k_{+n}$ will denote ....".

IN the article appearing on p. 372 of the April 28 issue of Nature entitled "Determination of Molecular Weights of Gelatin by Scattered Light Measurements", by B. E. Tabor, lines 20-23 should read ". . . $\bar{M}_{w}$ with respect to the intrinsic viscosity. The replacement of the $0.5 M$ saline, used by Stainsby, with $1 M$ potassium thiocyanate...". 